Case Report

\title{
Adult Colonic Intussusception Due To A Lipoma Mimicking Carcinoma
}

\section{Dhan Vikram Karkee}

Department of Surgery, Sumeru Hospital Pvt. Ltd., Lalitpur, Nepal

\section{ABSTRACT}

Adult colonic intussusceptions are rare and most of them are caused by malignant lesions. Presentation varies and preoperative diagnosis is unusual. We describe a case of 42 year gentleman with a colonic intussusception due to a lipoma. The lipoma was located in the descending colon and appeared like a carcinoma on colonoscopy. Though CT scan correctly diagnosed the entity intussusception and benign lipoma in this case, a formal bowel resection was performed because of suspicious colonoscopic features and high incidence of malignancy in the colonic intussusception. This case is unique, in the sense that, it mimicked carcinoma, it was on the left colon and it progressed to intussusception during hospital stay.

Key words: Colon; Intussusception; Lipoma; Resection
Copyright: This is an open-access article distributed under the terms of the Creative Commons Attribution 4.0 International License, which permits unrestricted use, distribution, and reproduction in any medium, provided the original author and source are credited.

\section{Correspondence:}

Dr. D V Karkee, MBBS, FRCSED, DMAS, DMAS

Consultant General Surgeon

Sumeru hospital, Dhapakhel, Lalitpur, Nepa

ORCID ID: 0000-0001-7573-5624

Email:dvkarkee@gmail.com

Submitted: $24^{\text {th }}$ March 2018

Accepted: $15^{\text {th }}$ July 2018

Published: $1^{\text {st }}$ December 2018

Sources of Support: None

Conflict of Interest: None

Citation: Karkee DV. Adult colonic intussusception due to a lipoma mimicking carcinoma. Nep Med J 2018;1:118-20. DOI: 10.3126/nmj.v\%vi\%i.21599

\section{INTRODUCTION}

Adult intussusception represents only $5 \%$ of all intussusceptions, ${ }^{1}$ of them $33 \%$ are located in the colon ${ }^{2}$ and caused by malignancy in $43 \%$ to $80 \%$ of cases. ${ }^{3}$ We report a case of colonic intussusception secondary to a lipoma that looked like a carcinoma on colonoscopy. Colonic lipomas are commonly located in the right hemicolon and rarely present as intussusception, however, in this case the lipoma was found in the descending colon and caused intussusception while patient waiting for CT scan.

\section{CASE REPORT}

A 42 years-old gentleman was referred to us by a physician for the management of descending colon carcinoma that he had suspected on colonoscopy. He had seen a $5 \mathrm{~cm}$ mass in the descending colon $40 \mathrm{~cm}$ from the anal verge that was fungating, ulcerated and bled to touch. He was absolutely sure about the mass being carcinoma and had taken biopsy. 


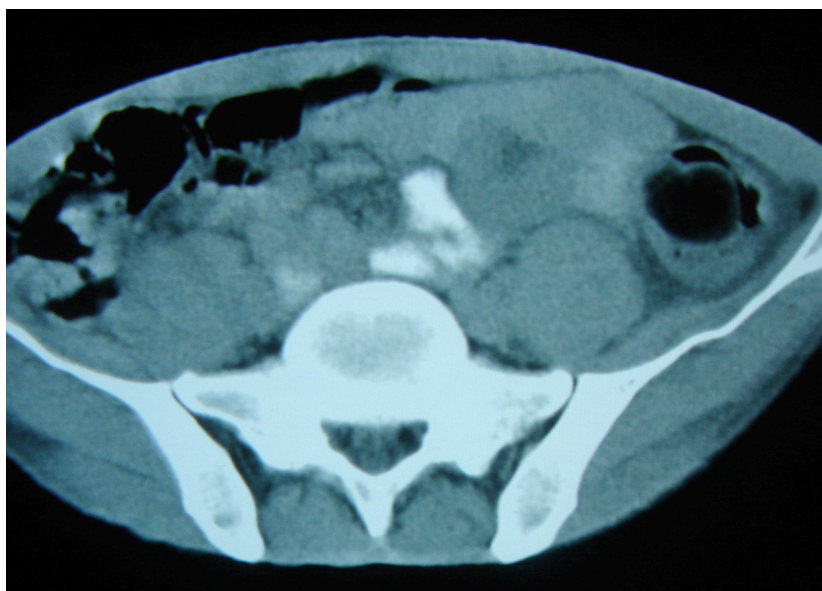

Figure 1: CT scan showing intussuscepted segment and colonic mass

On inquiry, patient had a month history of vague left sided abdominal pain and occasional episodes of fresh blood per rectum. Appetite was normal but he had lost about $2 \mathrm{~kg}$ weight. Examination revealed a thin built gentleman without pallor, icterus or supraclavicular enlarged nodes. Abdominal examination was normal. Metastatic work up, otherwise, was normal. He was admitted for surgery and abdominal CT was due. Few hours prior to $\mathrm{CT}$ scan, patient experienced a crampy hypogastric pain. Examination immediately after CT revealed a non tender, mobile mass of about $6 \mathrm{~cm}$ in the left lumbar region. CT scan (fig. 1) revealed a target lesion in the sigmoid colon with a low attenuated central mass suggestive of colonic intussusception due to lipoma. Since he had no obstructive features, clinical diagnosis of sigmoid colon carcinoma was made and laparotomy was planned on the next day.

On laparotomy, sigmoid colon intussusception was confirmed (fig. 2) and the descending colon was the intussusceptum. A formal left hemicolectomy with lymphovascular clearance was performed. While mobilizing the colon, intussusception was reduced spontaneously that was however not intentional. Cut opening the bowel, a $4 \mathrm{~cm}$ ulcerated mass without an obvious peduncle was noted (fig. 3A). Postoperatively, patient recovered well and discharged on the $7^{\text {th }}$ postoperative day. Colonoscopic biopsy revealed non-specific chronic inflammation and operative specimen was reported as colonic lipoma with congested bowel wall (fig. 3B).

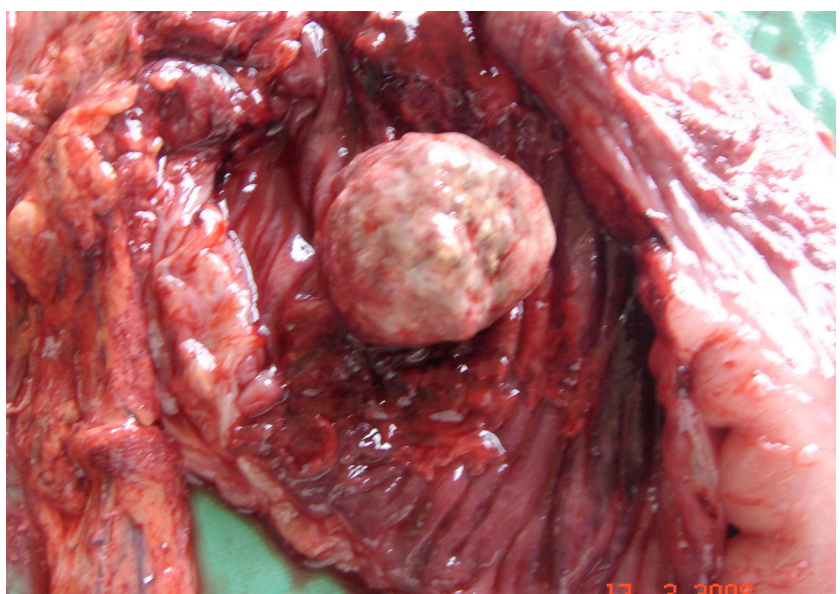

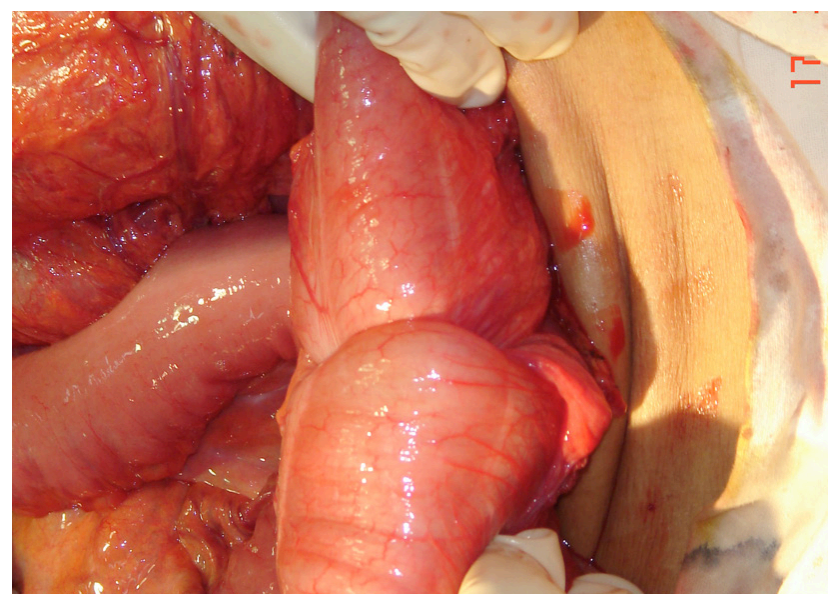

Figure 2: Colocolic intussusception showing intussusceptum and intussuscepien during operative procedure.

\section{DISCUSSION}

Adult intussusception is rare, representing $5 \%$ of all intussusceptions and accounting for about $1 \%-5 \%$ of all intestinal obstructions in adults. ${ }^{1}$ It can be divided into small bowel and large bowel intussusception. In an 18 years retrospective review by Erkan et al, large bowel adult intussusceptions were found less frequently (33\%) than small bowel. ${ }^{2}$ Seventy to $90 \%$ of adult intussusceptions have a demonstrable organic cause, $60 \%$ due to neoplasm and, of them $60 \%$ are malignant. ${ }^{3}$ Large bowel intussusception is more likely ( $43 \%$ to $80 \%$ vs $14 \%$ to $47 \%$ ) to have a malignant cause than small bowel ${ }^{3}$ However, our patient had intussusception due to a benign lipoma that appeared on colonoscopy like a carcinoma. At least two such cases of colonic lipomas mimicking carcinomas have been reported. ${ }^{4,5}$ Such appearance is thought to be due to the ulcerated and necrotic mucosal surface of the colon overlying the lipoma and also due to the loss of "cushion or pillow sign" of lipoma secondary to fibrosis. ${ }^{4,5}$

Colonic lipomas are the third most common benign neoplasms with a reported incidence ranging from $0.2 \%$ to $4.4 \%$ and preceded only by hyperplastic and adenomatous polyps. ${ }^{5,6}$ In the Mayo clinic series, $46 \%$ colonic lipomas were discovered incidentally in resected specimens for other diseases. ${ }^{7}$ Ninety percent of the

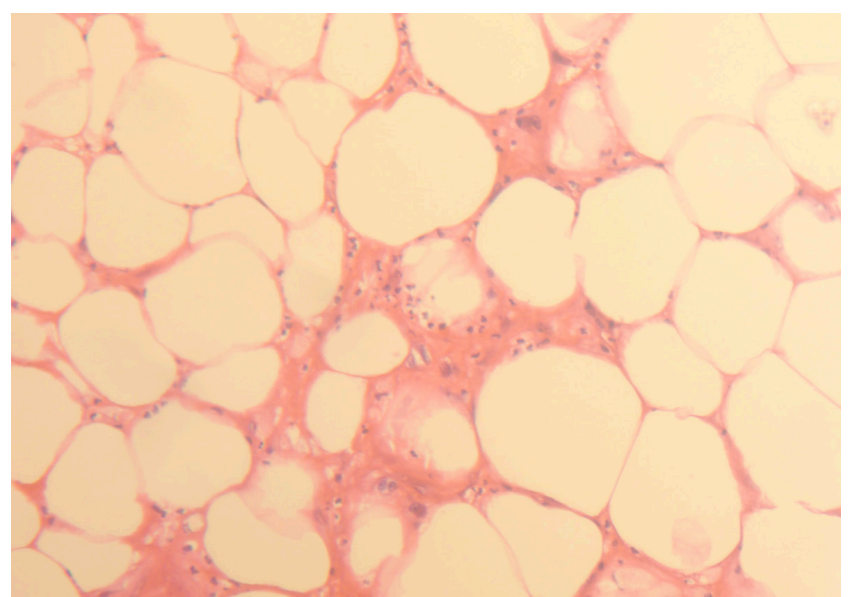

Figure 3A: A broad based colonic mass with ulcerative and fungating surface. B. Histopathology of the mass showing mature adipose tissue (HE stain, X100). 
colonic lipomas arise submucosally, $70 \%$ are localized in the right hemicolon, $10 \%-20 \%$ are multiple and may range from $2 \mathrm{~mm}$ to $30 \mathrm{~cm}$ in size. ${ }^{8}$ Though frequently small and asymptomatic ${ }^{9}$, only one quarter of colonic lipomas will present with symptoms ${ }^{5}$ especially when they exceed $2 \mathrm{~cm}$ in size. ${ }^{8}$ Most commonly they present with abdominal pain, constipation and rectal bleeding, however, surgical emergencies like intussusception, obstruction and massive haemorrhage are rare. ${ }^{8}$ Our patient was unique in having the lipoma located in the descending colon and it caused intussusception while patient being staged for carcinoma.

A preoperative diagnosis of intussusception is rare in adults because of varying presentations; hence ultrasound and CT scan have been recommended to improve the diagnostic accuracy. ${ }^{1}$ Recent series have reported $40 \%$ to $80 \%$ preoperative diagnosis especially in the presence of CT scan. ${ }^{2}$ CT will demonstrate a "target mass" or a "sausage shaped mass" while a "pseudokidney sign" or a "doughnut sign" will be seen in ultrasound. ${ }^{10,11} \mathrm{CT}$ scan is considered better with an accuracy rate of $78 \%$ to $100 \%$ in the diagnosis of intussusception. ${ }^{1,11}$ CT correctly diagnosed both intussusception and lipoma in our case; however, we were reluctant to accept the diagnosis because of clinical and colonoscopic findings. Even on CT, a lipoma could be mistaken for adenocarcinoma, lymphoma and metastasis especially in cases of intussusception. ${ }^{12}$ On colonoscopy, a lipoma exhibits a "cushion sign" or "pillow sign' (pressing forceps against the lesion results in depression or pillowing of the mass) and "naked fat sign"(extrusion of fat at biopsy site ${ }^{4,7}$ which may be absent because of repeated inflammation and fibrosis. ${ }^{4,5}$

All adult intussusceptions require surgical resection because of high incidence of pathologic lesion; however, controversies exist regarding the extent of resection and reduction of intussusception prior to resection. ${ }^{3} \mathrm{~A}$ formal bowel resection with lymphovascular clearance is recommended because of high incidence of malignant aetiology. ${ }^{1}$ It is better not to attempt the reduction prior to resection ${ }^{13}$ because of danger in bowel perforation, tumour seeding and venous embolization of malignant cells. ${ }^{7,14}$ Despite being aware of 'no reduction prior to resection', our intussusception reduced spontaneously at the time of colonic mobilization probably it was of recent onset and not much advanced. Reduction may be indicated only in a case of colorectal intussusception to avoid abdominoperineal resection. In this situation anterior resection will be feasible after reduction if the lower rectum is not necrosed. ${ }^{10}$

\section{CONCLUSIONS}

Colonic lipomas are rare and less commonly located in the left colon. They may cause adult intussusception and mimic a carcinoma.

\section{REFERENCES}

1. Azar T, Berger DL. Adult intussusception. Ann Surg 1997; 226:13438. $\underline{\text { Crossref }}$

2. Erkan N, Hacryanh M, Yildirim M et al. Intussusception in adults: an unusual and challenging condition for surgeons. Int J Colorectal Dis 2005;20:452-56. Crossref

3. Takeuchi K, Tsuzuki Y, Ando T et al. The diagnosis and treatment of adult intussusception. J Clin Gastroenterol 2003;36:18-21. Crossref

4. Martin P, Sklow B, Adler DG. Large colonic lipoma mimicking colon cancer and causing colonic intussusception.Dig Dis Sci. 2008;53:2826-7 Crossref

5. Huch KC, Lee TH, Kim SM et al. Intussuscepted sigmoid colonic lipomas mimicking carcinoma. Dig Dis Sci 2006;51:791-95. Crossref

6. Vecchio R, Ferrera M, Mosca F et al. Lipomas of the large boewl. Eur J Surg 1996;162:915-9. Crossref

7. Taylor BA, Wolff BG. Colonic lipomas. Report of two unusual cases and review of the Mayo Clinic experience 1976-1985. Dis Colon Rectum 1987;30:888-93. Crossref

8. Koray A, Cem T, Funda $\mathrm{O}$ et al. symptomatic intestinal lipomas requiring surgical interventions secondary to ileal intussusception and colonic obstruction: report of two cases. Ulus Travma Acil Cerrahi Derg 2007;13:227-31.
9. Bombi JA. Polyps of the colon in Barcelona, Spain. An autopsy study.Cancer 1988;61;1472-6. Crossref

10. Elabsi Mohamed, Amraoli Mohemed, Elouannani Mohemed et al. Colorectal intussusception secondary to sigmoid carcinoma in an adult. Southerm Med J 2007;100:1039-41. Crossref

11. Gayer G, Zissin R, Apter S et al. Pictorial review: adult intussusception - a CT diagnosis. Br J Radiol 2002;75;185-90. Crossref

12. Buetow PC, Buck IL, Carr NJ et al. Intussuscepted colon lipomas: Loss of fat attenuation on $\mathrm{CT}$ with pathologic correlation in 10 cases. Abdominal imaging 1996;21:153-6. Crossref

13. Eisen LK, Cunningham JD, Aufses Jr AH. Intussusception in adults: institutional review. J Am Coll Surg 1999;188:390-5. Crossref

14. Nagorney DM, Sarr MG, Mcilarth DC. Surgical management of intussusception in adults. Ann Surg 1981;193:230-6. Crossref 